\title{
Futurenaut Training Program 1966
}

Projected: A Film-Strip of the Sunshine State ca. 1974

\section{Special Commander Lawrence:}

"Filmed sunshine in '74 was an aspect of your love.

But these faded and mellow rays overexposed you, Futurenauts, and there you disappeared,

leaving these bottles of tanning oil on the beach at Daytona beside your cellophane soft-packs of Winstons, which even more than our latest technology hold their decades inside.

Here, the oil on your fingers as you smoked soaked your camel-brown filters

and the hot cement beside the pool dried the chlorine into your heels.

Imagine how these towels feel and smell as they dry by the pool.

An understanding of the tanning oil, the Winstons and the towels, Futurenauts, will bring you to years. To what you've trained for.

Remember, there are tears in the decades. And much happiness." 
Projected: Film Footage of Los Angeles, ca. 1978

"Now some words from Special Commander Delano."

"Thank you, Commander.

This is Los Angeles. 1978. Your point of entry.

Your El Coyote tamales and margaritas.

A meal in March of that year.

The Seven Veils Club.

The Sunset Strip.

Later, on your leopard blanket, under the mirrored bar, in your two bedroom apartment at the El Cadiz on Sycamore. Your L.A. Apartment Living poster.

Your Sunset Magazines.

These bottles of summer lotions under this bathroom sink, those whose flip-tops are dust and splattered cocoa-butter, these account for your previous year. Your previous summer.

Again, a supreme understanding of the meal, the blanket, and the bottles,

an understanding of objects in locale and time, may bring on severe melancholia,

but will allow you to complete your mission:

This brown '77 Datsun B-210 driving Franklin Avenue in Hollywood, returning from a day at The Farmer's Market at Fairfax and 3rd. 
Notice the flashing of sunlight here and here, off the hood and passenger-side door.

Even this glance off the metal hinge on the young passenger's sunglasses.

You see, the Datsun and the moment pass as the years pass.

Futurenauts, here is why the stars have turned that sickening brown.

And why all of Heaven is now every shade of brown." 